\title{
An Educational Strategy to Promote Economic Opportunity in Impoverished Urban Areas
}

\author{
M. Kathleen Cripe ${ }^{1}$, Kenneth L. Miller ${ }^{1}$, Susan M. Miller ${ }^{2}$, Crystal Ratican ${ }^{1}$, Sean Ratican ${ }^{3}$ \\ Youngstown State University ${ }^{1}$, Miami University ${ }^{2}$, Kent State University ${ }^{3}$ \\ USA
}

\begin{abstract}
Authors argue that the inner-city poverty characterizing most U.S. cities can be remediated through strategic investments in education. A practical and achievable approach for invigorating inner-city economies and creating financial opportunities for residents lies in providing equitable and high-quality educational experiences. Research suggests that innercity schools frequently fail to attract and retain highquality teachers and that teacher education programs must ensure that graduates possess the specialized knowledge, skills, and dispositions required to meet the unique needs of inner-city students. Authors describe an assessment model employed in the teacher education program at a mid-size, midwestern university that was designed to: identify and redress students' misperceptions of urban schools, misunderstandings of cultural dynamics, and dispositional inadequacies; and inform curricular modifications designed to ensure student attainment of knowledge, skills, and dispositions required for effective teaching in urban schools. Based on data obtained from assessments, authors present recommendations for enhancing the preparation of urban school teachers with the ultimate goal of improving economic opportunities and quality of life for all inner-city residents.
\end{abstract}

\section{Introduction}

The history of American cities reveals general increases in population growth/density, cultural diversity, personal wealth, and opportunities for individual financial prosperity. However, these trends are not universal. During the twentieth century, social, political, and economic dynamics reshaped the fortunes of many American cities that were once prosperous and, perhaps more importantly, restructured economic landscapes within cities to create egregious financial disparities. Amid robust prosperity for many, people of color were disproportionately excluded [1] and became stranded on inner city islands of poverty and economic withering. Whether caused by racism, "white flight," job exportation, or systemic inaccessibility to resources required for financial success, inner city poverty has become a dominant and stable feature of urban landscapes across the United States.

Irrespective of the dynamics that created and maintained inner city poverty, solutions to remediating it are well known, yet often rejected because of personal and/or social costs, inadequate resources, and social apathy. Despite these hurdles, a widely-adopted and research-based solution revealed that educational attainment is a critical precursor to individual financial security and economic revitalization of impoverished urban centers [2,3]. Yet, educational attainment is not a standardized construct (e.g., attainment of a high school diploma from school A may not have the same stature or provide the same opportunities as a diploma from school B). This disparity forces an examination of how "educational equity" and "educational quality" serve to create opportunities for some and limit those same opportunities for others. The results of such examinations also reveal strategies for improving educational attainment, personal opportunity, financial self-sufficiency, and community-wide economic health and well-being.

\section{Economic Impact of Investments in Education}

Previous studies demonstrated that investments in the education of school-aged children can increase cognitive and non-cognitive development, thus resulting in an increased return on investment as the child enters the workforce [4]. The productivity and economic impact of the workforce increased as businesses and government entities invested in the 
education of the workforce [5]. Heckman and Carneiro [6] found that preschool programs return $\$ 5.7$ for every dollar spent on education through the age of 27 , and $\$ 8.7$ is returned for every dollar spent over the remainder of the children's career.

Investing in education is an efficient utilization of a community's resources. During a 50-year period from 1966 to 2015, "the average rate of return on investments within stocks and bonds was reported at 2.4 percent versus 10.5 percent overall private return to investment in education" [7]. The economic impact of improving the quality of education for communities and states across the U. S. can have a marked impact on the local, regional, and national economies. Although different results can vary from state to state depending on the current level of education, and the estimated economic outcomes can be imprecise, the net return on investment is estimated to be positive regardless of state. Increasing the quality of the lowest-performing states to the level of the best-performing state in the U. S. could result in an estimated Gross Domestic Product (GDP) improvement of 3.5 to 10 percent per state [8]. The states and regions with the lowest ranking schools can benefit the greatest from an increase in quality teacher presence; higher teacher quality will result in increased overall gains within the workforce of that district, state, or region. Quality teachers lead to higher educational attainment of students, which in turn impacts the economic cycle of a community's economy.

Government entities that invest in the education of the community's workforce have seen increased economic growth [5]. Increased income and wages for a workforce are a direct result of increased education in the workforce as a whole, which in turn creates higher property values, increased tax revenue, and thus increased funding to schools through the higher tax base. Strategic investments in the education system of a community can spawn this cycle of economic growth, which motivates businesses to locate and expand within the areas around an educated workforce. The more educated the workforce becomes, the higher the demand for skilled workers becomes, which leads to a more significant economic impact through increased wages which results in more disposable income being invested within the local economy. Put simply, the government can increase household per capital income by prioritizing expenditures that increase the quality of education within local schools [4]. Therefore, the "increase in the labor supply probably stimulates labor demand by at least two-thirds the supply increase. This is because additional labor attracts employers, and additional higher skilled labor attracts employers with more skilled jobs" [9]. These investments lead to a more productive economy, and "a more productive economy can support both higher wages and higher profits... productivity rises with investments in infrastructure and workers, with investments in education that raise educational achievement providing a major boost" [5].

\section{Need for High-Quality Teachers in Urban Schools}

Many students enter the teaching profession with profound misperceptions of urban schools and the cultural dynamics that operate in these environments [10]. Additionally, personal biases and discriminatory behaviors limit the effectiveness of teachers [11] who elect to work in urban schools, which perpetuates educational inequalities and causes many to leave urban schools for other positions [5, 18]. These dynamics have operated for decades, if not centuries, to create inequitable learning environments for many urban school students and perpetuate the vicious cycle of inner-city poverty.

Compounding these challenges is one of staffing qualified teachers and retaining them for more than three years [16]. A shortage of qualified teachers is increasingly placing burdens on teacher preparation programs to prepare candidates for the challenging work in urban school districts. Teacher education programs need to recruit and prepare candidates with the strategies and skills needed to work in diverse settings [5].

\section{A Strategy to Ensure Educational Equity and Quality in Urban Schools}

Ensuring educational equity and quality in urban schools requires competent teachers. This paper describes an assessment strategy employed in the teacher education program at a mid-size, midwestern university to promote teaching competence in urban schools, which is undergoing study from 2018 through 2021. This strategy used (a) longitudinal assessments to identify and redress students' misperceptions of urban schools, misunderstandings of cultural dynamics, and dispositional inadequacies; and (b) assessment results to inform curricular modifications designed to ensure student attainment of knowledge, skills, and dispositions required for effective teaching in urban schools.

The primary goals of the study were to: (a) identify and deliver educational interventions designed to produce knowledgeable, skilled, and dispositionallycompetent teachers to staff inner city schools; (b) 
identify data-driven recommendations for promoting teaching competence in urban schools (some of which are included in this article); (c) provide teacher education students with learning experiences and accurate knowledge of urban schools that could positively influence job-seeking and job-retention decisions; and (d) promote educational equity and a high quality education for inner city students.

Long-term objectives are to increase inner-city job opportunities, enhance diversification of business ownership, promote the economic recovery of inner cities, and create an improved quality of life for all people living in urban environments.

\section{The Assessment Model}

Participants were all students enrolled in the teacher education program at a mid-size, midwestern university during academic years 2018-2021. The Pre-Clinical Candidate Perceptions of Urban Schools Scale (PCCPUSS) was developed by the authors to assess students' perceptions of urban schools, students, and teachers. Items selected for inclusion in the scale were drawn from the research literature and authors' collective experiences as educators working with students before and after their urban field experiences. The final survey consisted of thirty-three items to which participants were asked to respond on a six-point Likert-type scale $(1=$ strongly disagree to $6=$ strongly agree). Some items were worded positively and others negatively; select items were recoded prior to analysis to establish a consistent response directionality.

Students completed the PCCPUSS in a First-Year Experience (FYE) course at the beginning of their first semester in order to assess their perceptions of urban schools (specifically in three areas: urban schools, students, and teachers) and two posttests following completion of required education courses during their second and third years. This longitudinal design was used to assess changes in students' knowledge, skills, and dispositions as they matriculated the teacher education program.

Results of this study were used to: (a) inform and create programmatic changes designed to improve students' effectiveness in urban school settings, (b) spur a qualitative study designed to more comprehensively assess teacher education students' knowledge, skill, and dispositional strengths and limitations, and (c) create recommendations for enhancing urban school teaching competence in teacher education programs.

\subsection{Results of a Qualitative Assessment}

Driven by findings from initial assessments, other full-time faculty in the Department of Education at three of the authors' home institution participated in a 2018 qualitative study designed to assess faculty perceptions of urban schools. Information was collected about: (a) faculty perceptions of students' experiences, (b) faculty experience levels in working with diverse students, (c) classroom pedagogies utilized to help students to develop greater awareness of diversity and multiculturalism; and (d) strategies for promoting teacher empathy, which ranged from building lessons around the students' needs to direct teaching/modeling.

Based on all survey findings, new program initiatives were created, and a new course was developed to help meet the diversity training needs of teacher education students.

\section{Recommendations}

Based on findings from the current study, authors propose four strategies designed to enhance the preparation of urban school teachers.

1. Comprehensively and rigorously evaluate teacher education program applicants related to personal beliefs, dispositional fitness, cultural competence, intellectual capacity, and teaching ability at regular intervals throughout the training program. These assessments must be conducted prior to program admission and at key matriculation junctures (i.e., admission to upper division, admission to student teaching, eligibility for licensure) in order to insure target levels of personal and professional competence on all dimensions as well as readiness for independent teaching practice. Both program faculty and practicing teachers should serve as evaluators in these processes and should be thoroughly trained in evaluation procedures to insure objective results. Evaluators must be assured that their primary responsibilities are to promote the development of student teachers and to protect students (and prospective students) from harm caused by teacher incompetence. As such, evaluators must understand that they serve as professional gatekeepers, that they must use their evaluative authority in the best interests of both teachers-intraining and the students they serve. Finally, evaluators must be assured that they will not be subjected to negative consequences for providing negative evaluation feedback or for not recommending a student/student teacher for licensure. 
2. Implement both a stand-alone course and regular immersion experiences throughout the teacher education curriculum that provide information and strategies for working effectively with students from all racial, cultural, ethnic, socioeconomic, religious, disability, and family structure groups and configurations. These learning experiences must provide "safe" opportunities for students to discuss personal belief systems about people different from themselves, explore the rationality and accuracy of such beliefs, consider implicit and/or explicit cultural biases that may result from such beliefs, and examine how such beliefs/biases may affect their efficacy as future teachers. Such discussions must be encouraged without the threat of a punitive response; however, misperceptions, irrational beliefs, and cultural biases must be challenged in a manner that promotes selfreflection as well as both personal and professional growth. Evaluations of personal beliefs, perceptions of others, and cultural bias must be conducted throughout the training program with the goals of using data from such instruments to inform training practices and assess students' growth.

3. Require teaching practicum experiences in urban, suburban, and rural school systems. Prior to student teaching, students must be provided with meaningful opportunities (multi-day experiences) to interact with students, teachers, and administrators in all three school settings. The primary goals of these practica are for students to gain knowledge of similarities and differences in school policies, professional norms, cultural dynamics, teaching practices, and their personal comfort/discomfort levels in all three settings. Per a required class assignment, results of these experiences should be shared in class discussions and feedback from both instructors and classmates should be provided.

4. Mandate an urban school student teaching experience for a minimum of one semester. Although not practicable in all teacher education programs, this mandate is not only feasible in most programs, but also critical for the development of competent urban school teachers. Research findings indicate that a sustained teaching experience in urban schools (with program support) promotes a deep understanding of cultural dynamics that operate in the lives of students and their families [7, 12], rectifies misperceptions about urban school students, teachers, and environments [7, 12], fosters an appreciation for needs of urban school students and their families [13], promotes confidence in abilities to teach effectively [14], and cultivates a desire to serve the needs of students, families, and local communities [7, 12, 15]. With 13,491 U. S. public school districts located in urban centers [17] the mandate for an urban school student teaching experience is warranted.

\section{Conclusions}

Authors have argued that fundamental keys to individual financial security in urban settings and innercity revitalization can be addressed by insuring "educational equity" and "educational quality" in urban schools and particularly in inner-city schools. Authors have further argued that these conditions are best achieved by insuring teacher competence and a reliable supply of qualified teachers in urban schools.

Just as racism, inequality, systemic poverty, and economic injustice are not accidents, nor are educational equity, a quality education, financial security, and economic revitalization. All of these conditions require intentional actions to bring them to fruition. Insuring that urban school students receive a high-quality education delivered by highly competent teachers is an action that can and must be achieved if these students and their families are to enjoy economic self-sufficiency and the renewal of their communities.

\section{References}

[1] Jonathan, W., and Worrel, F. (2020/2021). "How talented low-income kids are left behind". Phi Delta Kappan, 102(4), 26-29.

[2] Foster, M. (2004). "An innovative professional development program for urban teachers". Phi Delta Kappan, 401-406.

[3] Jackson, M., Green, D., Martin. L., and Fasching-Varner. K. (2016). "Band-aids don't fix bullet holes". Democracy and Education, 24(2), 1-6.

[4] Delalibera, B., and Ferreira, P. (2018). "Early childhood education and economic growth". Journal of Economic Dynamics and Control, 98, 82-104.

[5] Berger, N., and Fisher, P. (2013). "A well-educated workforce is key to safe prosperity". Economic Policy Institute, 22(1), 1-14

[6] Heckman, J., and Carneiro, P. (2003). "Human capital policy". National Bureau of Economic Research.

[7] Psacharopoulos, G., and Patrinos, H. (2018). "Returns to investment in education: A decennial review of the global literature". Policy Research Working Paper, World Bank Group. 
[8] Hanushek, E., Ruhose, J., and Woessmann, L. (2017). "Economic gains from educational reform by U. S. States". Journal of Human Capital, 11(4), 447-487.

[9] Bartik, T. (2009). What Works in State Economic Development? Growing the State Economy: Evidence-Based Policy Options, 15-27.

[10] Schaffer, C., Gleich-Bope, D., and Copich, C. (2014). "Urban immersion: Changing pre-service teachers' perceptions of urban schools". The Nebraska Educator: A Student-Led Journal, 19.

[11] Groulx, J. G. (2001). "Changing preservice teacher perceptions of minority schools". Urban Education, 36(1), 6092.

[12] Voell, P. (2000). "The Learning Curve: First Year Teachers Use Every Tactic from Personal Mentoring Sessions to Old Fashioned Trial and Error to Learn Their Own Lessons in the Classroom". Buffalo News, pp. C1, C2.

[13] Truscott, S, and D Truscott. (2005). "Differing circumstances, similar struggles: Commonalities that define urban and rural education". Phi Delta Kappan, 87(2), 123-30.

[14] Hynes, J. L., and Socoski, P. (1991). "Undergraduates' attitudes toward teaching in urban and non-urban schools". Paper presented at the annual meeting of the Eastern Educational Research Association. Teachers. Phi Delta Kappan, 401-406.

[15] Proctor, T. J., Rentz, N. L., and Jackson, M. W. (2001). "Preparing teachers for urban schools: The role of field experiences". The Western Journal of Black Studies, 25(4), 219-232.

[16] Sutcher, L., Darling-Hammond, L., and Carver-Thomas, D. (2016). A Coming Crisis in Teaching? Teacher Supply, Demand, and Shortage in the US. Learning Policy Institute.

[17] Truscott, S., and Truscott, D. (2005). Comprehensive Handbook of Multicultural School Psychology. Hoboken, NJ: Wiley and Sons.

[18] U. S. Department of Education, Institute of Education Sciences, National Center for Education Statistics (20132014). Urban Education in America, NCES Number: 20200009. 